The Brock Review Volume 11 No. 2 (2011)

(C) Brock University

\title{
The Navigator
}

Merijean Morrissey

\section{Background}

THE NAVIGATOR is an ongoing body of work that is perhaps only half way towards completion and currently comprises several large paintings, drawings, etchings, photos and some 1/4-scale boat models that I have constructed. As an artist it is very difficult to predict when a concept has run its course. The project has taken many forms and tangents, but all the work addresses notions of loss and memory, especially as it relates to history and tradition. On a personal level, THE NAVIGATOR is a 'memento mori' homage to my father, an armchair traveler, and Irish romantic. It does not chart the course of his life, but rather examines ways that allow us to negotiate through and transcend cultural limitations. It confirms the decline of an objectifying, Eurocentric worldview. Taken as a whole, THE NAVIGATOR challenges the unified subject and places in its stead a matrix of constructive emblems. These chimera, galaxies, or stranded vessels float in poetic space referencing themselves to icons of Enlightenment systems of meaning, systems that have become unhinged from the stability of logic.

Broadly, the notions I am working with are a deconstruction of our linear received history. The continuum of barbarous or imperialist behaviours committed in our name by dominant hegemonic cultures as represented in such works as David Hurst's On Westernism, Irna Paris's Long Shadows: Truth, Lies and History and Dot Tuer's essay, Towards the Slaughterhouse of History: Working Papers on Culture, inform my work. However, as an artist who works with narrative, my narratives are fictions and closer to the form of the literary novel than to any historical or political text.

Central to this body of work are two tall narrow painted panels that loosely present a deconstruction of the history of expansionist culture. Symbols of its cannons - cathedral floor plans, classical urns, and trophies - are used to mark the loss of an exclusive dominant culture. While these emblems represent vestiges of a system of cultural navigation, their presentation without moorings locates them in a new firmament of transcendence. 
Two additional large paintings, also framed by classical bases and pediments depict life-sized winged chimera, WINDS OF CHANGE. These menacing mutated figures blow mightily as do the angels ancient cartographers used to show the prevailing winds. Their anxious presence corresponds to Western society's present and future engagement in a cataclysmic world reordering. THE NAVIGATOR investigates this troubled territory.

A series of paintings that depict the COSMOS, with its various constellations, astronomical objects and phenomena in the distant universe, bring a sense of wonder and beauty to THE NAVIGATOR. These COSMOS paintings are however, ironic reminders of a time span far greater than any other events chronicled or suggested by the work. These paintings also connect ideas about our newest age of discovery, as represented by views made possible by the Hubble telescope and the Advanced Camera for Surveys (ACS), with those of early sailors and vessels on more grounded voyages of plunder.

All the elements of THE NAVIGATOR depend on an ever-present black, the beauty of which consumes and surrounds its every feature. This rich limitless darkness derives from my continuing commitment to intaglio printmaking. The completed etchings that so far contribute to this body of work construct a dark oceanic space. From within the celestial night emerge myriad points that direct us toward the concrete world. Some of the etchings, as well as the paintings, are anchored by a checkerboard pattern that shifts between figure and ground. This device holds in careful balance the coexisting demands of pictorial order with a free-floating matrix that is fundamentally non-hierarchical.

My art practice, including IN NOMINE... and even the KIMONOS and KILIMS has attempted to address the dominant culture's need to colonize, to impose, to claim, to signify and codify ownership. Presently, I am engaged in producing THE NAVIGATOR'S COMEDY, a folio of 100 drawings, prompted by reading Dante's great poem, THE DIVINE COMEDY. In this work, the navigator/artist, re-visits, through a visual narrative, and through its metaphoric decent into the inferno, those historical and contemporary cultural sites of the dominant power's pillage.

\section{Current work}

The new intaglio prints, AN SEOLTOIR EIREANNACH/THE IRISH NAVIGATOR, completed at GSD in Ireland in August 2010, take another tangent and look at emigration from the "isle of home" as one more consequence of colonialism. There are eight completed prints in the suite. The "landscape" is represented in terms of our blue planet with the sea and cosmos as an 
interchangeable visual space. The primary imagery is the sea, its ships, ancient maps and sea monsters, and the star-filled heavens. While no one doubts the dangers involved in sailing on one of the Irish famine ships of the 1840-60s, my intention is to try for a many layered understanding of the imagery. For example, MAN OF WAR presents a Portuguese Man of War jellyfish whose tentacles grasp hold of a ship. The suggestion is not only are there are inherent dangers in early sea voyages, but that emigrants are vulnerable to the vagaries of other forces as well. I also posit the possibility that ships of the Armada get their just rewards.

OUTBOUND/ARGO NAVIS and INBOUND/ARGO NAVIS address the situation of most immigrants - they will never go home-they are always sailing on the sea of life. Seldom is this a chosen landscape. Argo Navis is a constellation in the southern hemisphere and represented in the re-drawn $17^{\text {th }}$ cent. star map in both of these prints.

EMIGRATION/IMMIGRATION is the only print in the suite that actually portrays land and represented by what we have come to think of as the "old" and the "new" world. The scale of its elements, land, empty rowboat, and sea monster construct an uneasy relationship, perhaps a catastrophic one. Of course, this is only one of many possible meanings.

CONSTELLATION is an invented map showing the constellation Argo Navis in the starrich Milky Way. Argo Navis, as legend asserts, is the mythical ship of Jason and the Argonauts that sails on its eternal voyage in search of the Golden fleece. Historical émigrés and contemporary ones as well are in the "same boat", if you will. The print is printed in silver ink and seems to disappear and fade, as do any clear memories of the past.

Some of the prints do not have complex readings, but acknowledge their "made in Ireland" label. Because my work usually takes narrative form, the print, TUNC, the Latin first word from the Book of Matthew, in the Book of Kells, is layered over the modern font of its translation THEN. The miniature chine colle' prints, GLANDELOW BOAT and CORACLE sit just at the edge of THE NAVIGATOR'S parameters.

AN SEOLTOIR EIREANNACH/THE IRISH NAVIGAOR suite of prints employs the centuries old method of intaglio. Most of the prints are etched in copper and a separate plate carries each colour.

As I continue work on THE NAVIGATOR, I know that I did in fact, come to understand something of my father's heart and that the Irish Sea was a very good place to continue the voyage. 


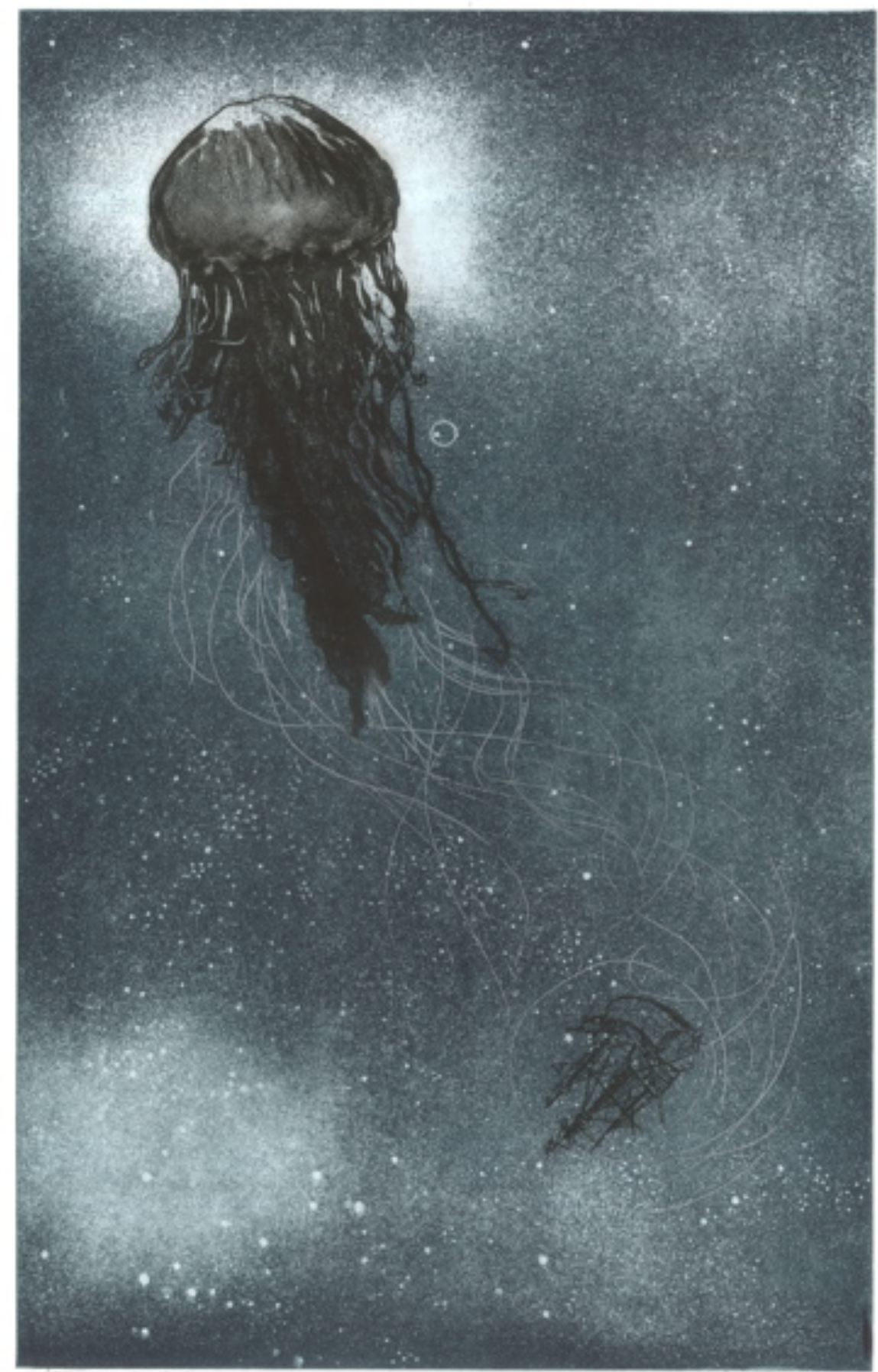

Plex of

7il: Therecely

Merijean Morrissey, Man of War (2010) 


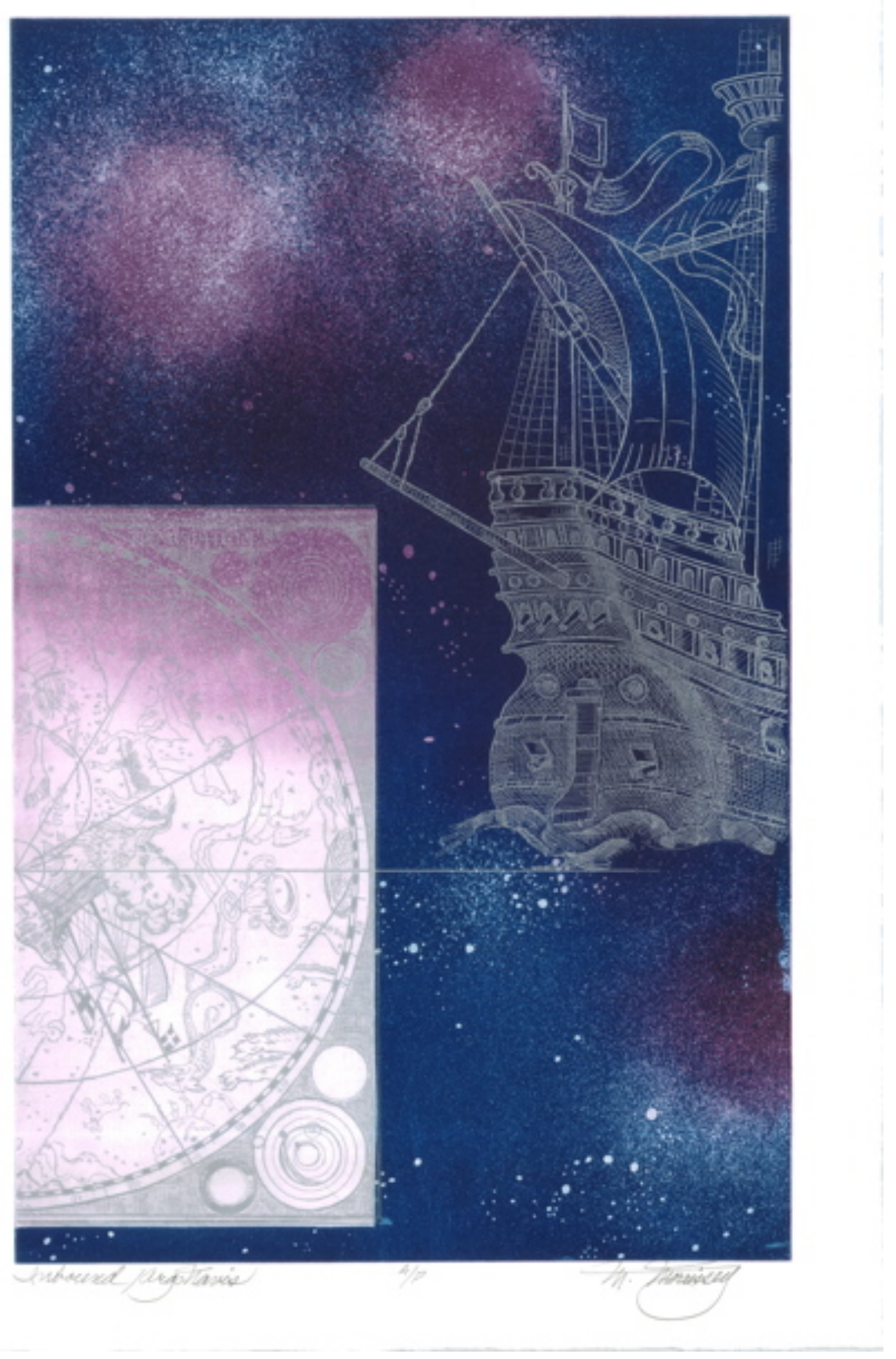

Merijean Morrissey, Inbound/ Argo Navis (2010) 


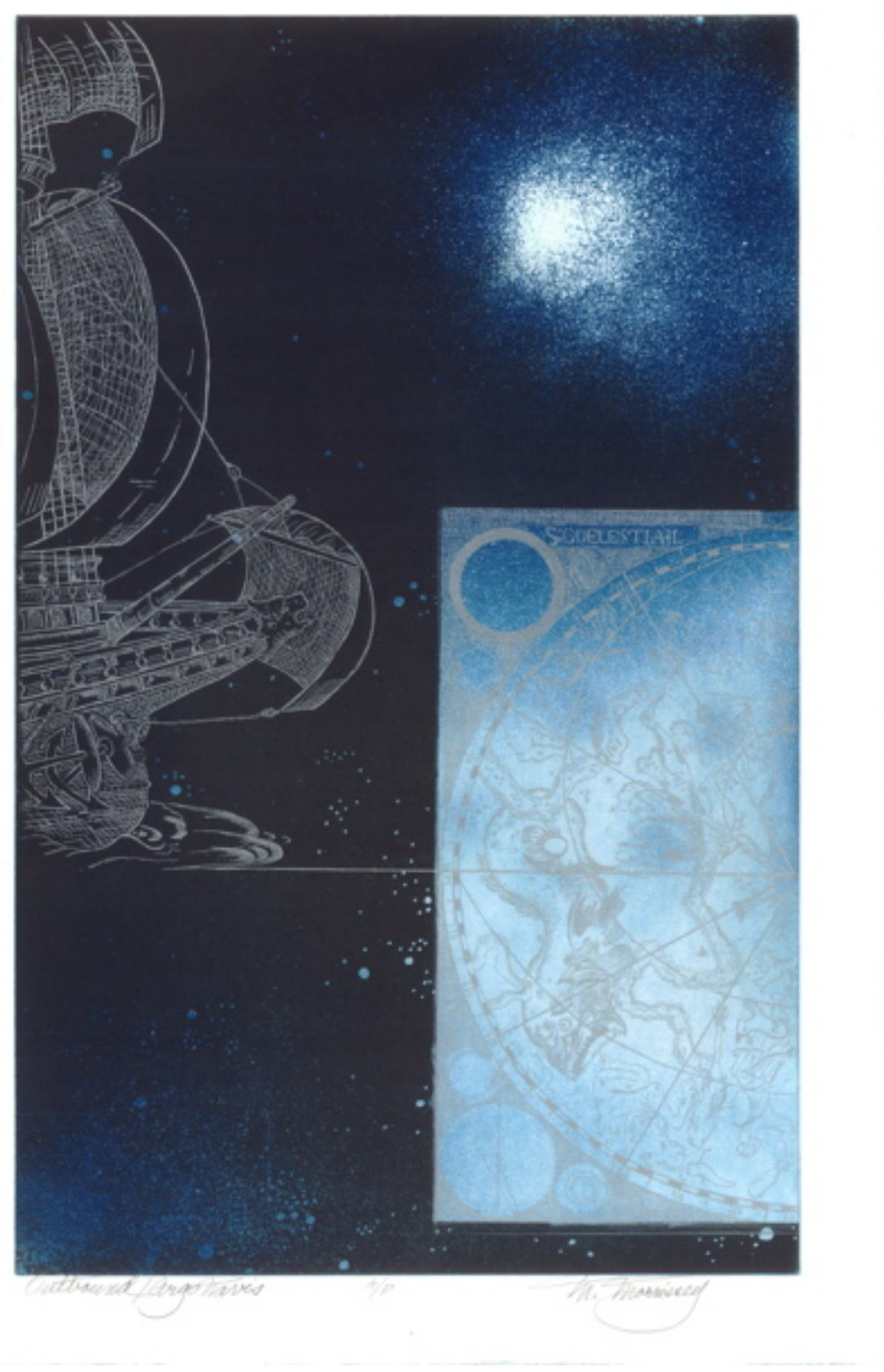

Merijean Morrissey, Outbound/Argo Navis (2010) 


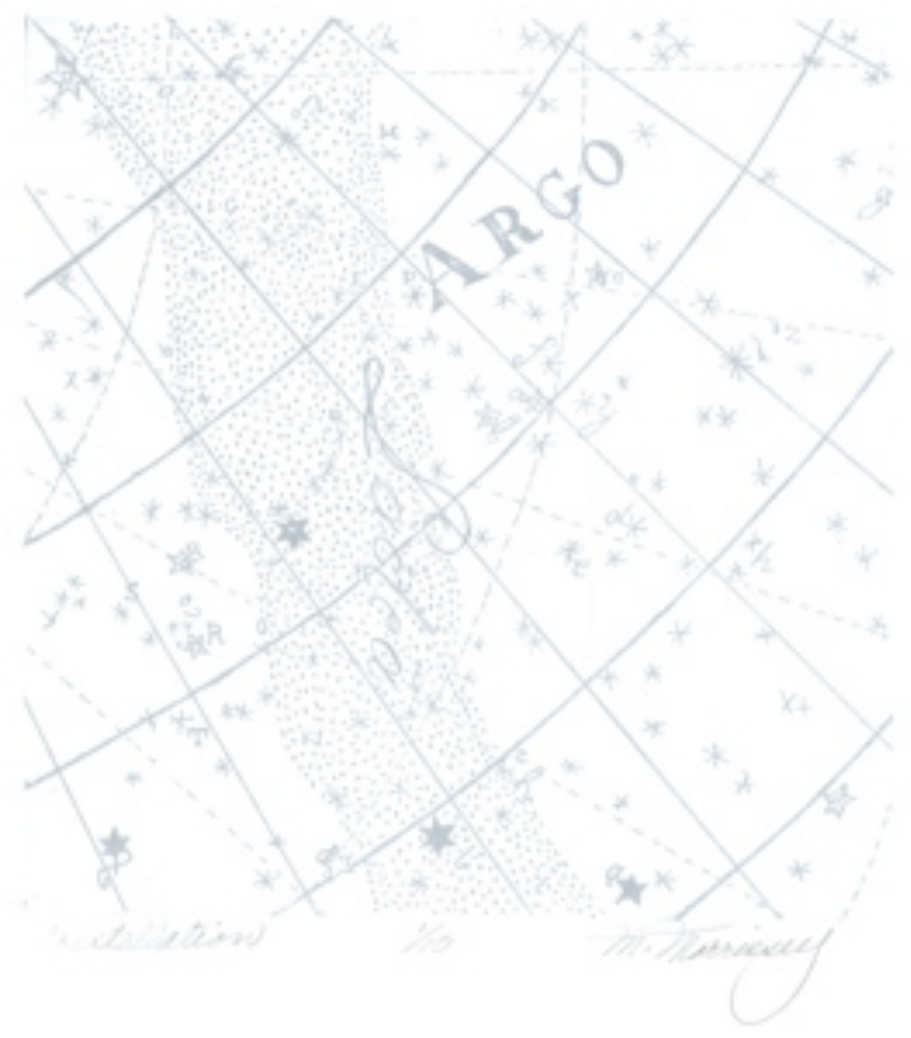

Merijean Morrissey, Constellation (2010) 


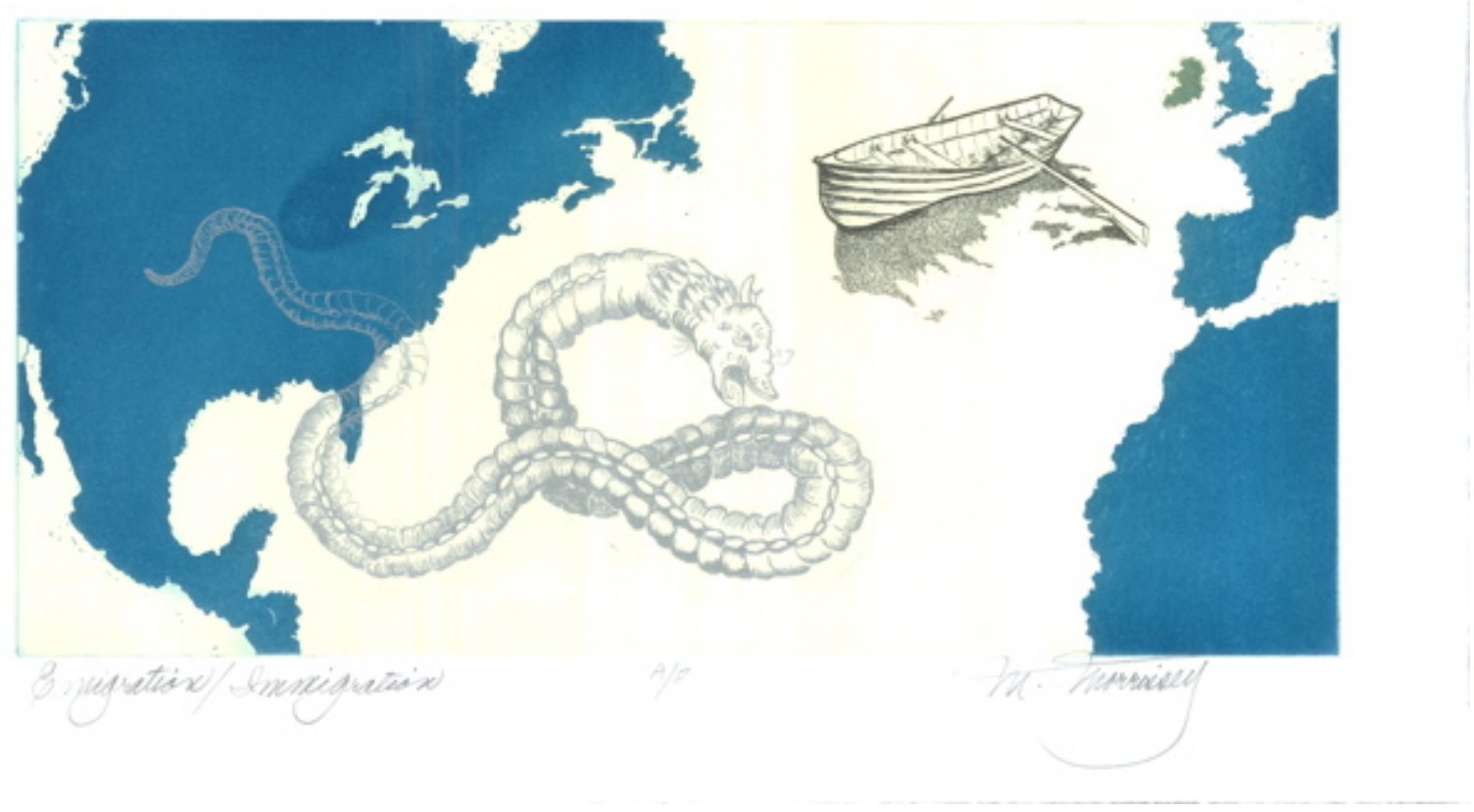

Merijean Morrissey, Emigration/Immigration (2010) 